\title{
The Ghana Project in Psychiatry: A Systematic Description of the Mental Health Services
}

\author{
Michael Atakora1* (D), Mdala Ibrahim², Emmanuel Asampong3 $^{3}$ \\ ${ }^{1}$ Faculty of Health Sciences, Institute of Clinical Medicine, UiT The Arctic University of Norway, Tromsø, Norway \\ ${ }^{2}$ Department of General Practice, University of Oslo, Oslo, Norway \\ ${ }^{3}$ Department of Behavioural Sciences, School of Public Health, University of Ghana, Legon, Ghana \\ Email: *Michael.atakora@gmail.com
}

How to cite this paper: Atakora, M., Ibrahim, M. and Asampong, E. (2020) The Ghana Project in Psychiatry: A Systematic Description of the Mental Health Services. Open Journal of Psychiatry, 10, 141-170. https://doi.org/10.4236/ojpsych.2020.104014

Received: July 21, 2020

Accepted: August 21, 2020

Published: August 24, 2020

Copyright $\odot 2020$ by author(s) and Scientific Research Publishing Inc. This work is licensed under the Creative Commons Attribution International License (CC BY 4.0).

http://creativecommons.org/licenses/by/4.0/

\begin{abstract}
Introduction: Mental health is a neglected field within the health care system in Ghana. Studies and public education focusing on mental health remain low, leading to poor knowledge and awareness of mental health among the population. Objective: The overall aim of this study was to provide a systematic description of mental health services in Ghana. Methods: A snowball technique was used to select a total of 42 mental health professionals from six hospitals for interviews. A structured questionnaire was used for data collection. Results: Major findings of this study include inadequate human and material resources; poor knowledge of mental health among the population; weak coordination between general practitioners and mental health professionals; inadequate mental health services in schools and prisons. Additionally, $54.8 \%$ of respondents reported limited mental health educational materials, and most schools (54.8\%) lacking trained resident mental health professionals. The main interventions for service delivery are taking over activities of daily living by nurses, problem assessment, and psychological interventions which achieved the same results (69\%). A tendency to consult faithbased healers and prayer camps; a lack of mental health research capacity, specifically research focusing on policies; and weakness in the organization and decentralization of mental health services in Ghana are among the common challenges to seeking care. Conclusion: Public mental health education on available resources and services is important. Capacity research focusing on dissemination and implementation of mental health policies can serve as the basis for addressing mental health challenges and improving service delivery in Ghana.
\end{abstract}

\section{Keywords}

Mental Health Service, Resources, Organization, Decentralization, Differentiation 


\section{Introduction}

The fundamental mandate of every health care system is ensuring quality service delivery for all with the aim to prevent disabilities and improve population health [1]. The delivery of mental health services in Ghana has been entrusted to the Ministry of Health, the Ghana Health Service (GHS), and the Mental Health Authority, which form the main mental health care system. These bodies are left with common challenges related to communication, collaboration, and organization and to planning systems towards improving mental health services in Ghana. This has contributed to the neglect of mental health services in Ghana for decades, which must be addressed due to the increasing number of people affected by mental disorders. Common factors that may explain the increase in mental disorders are associated with the mammoth challenges of limited resources, scant budgets for mental health service delivery, personal life pressures (unemployment, family, and marital life), inadequate mental health education among the population, and negative societal perceptions about mental health. According to a study by WHO, challenges associated with mental health service delivery are linked to a lack of research in this field, the wide treatment gap, poor management modalities, and weak mental health education [2].

The first mental health study in Ghana was conducted by Tooth in 1950, during the colonial era. This study focused on forms of neurosis and psychosis among West Africans, with four hundred cases documented. Tooth conducted ethnographic research on people living with mental disorders and seeking recovery by visiting rural shrines. Field in 1960 subsequently noted that after independence on 6 March 1957, the establishment of health institutions for the training of mental health professionals, mental health educational campaigns, and media attention were used to address mental health service challenges. Studies on mental health services in Ghana remain limited and in need of improvement [3].

Much effort has been made since 1990 to decentralize and integrate mental health service delivery into primary care. Yet little was achieved until 2012, when the Mental Health Act 846 was instituted. The Mental Health Act 846 prioritized moving mental health services from the institutional to the community level. However, this comes with the institutional challenges of limited resources, the weak organization of mental health services, weak decentralization processes of service delivery, and weak interventions to improve mental health service delivery. Although the implementation of the Mental Health Act 846 in 2012 brought some relief in the promotion of mental health services, few of those who require mental health services can access them, and this has led to a call for improvement in the delivery of mental health services in Ghana.

Research has shown that mental and substance use disorders are now the leading cause of disability in the world [4], and the global burden of disease is associated with mental disorders coupled with a large treatment gap [5]. Moreover, it is estimated that $70 \%$ of the global population who need mental health 
services do not receive care [6]. In most countries, including Ghana, the lack of mental health care may be attributed to inadequate human and material resources [7] [8]. The European Mental Health Declaration states that the promotion of mental health is a priority of the World Health Organization (WHO), and enhanced coordination between countries is considered a way to improve mental health service [9]. The WHO [10] has further stated that mental health service delivery should be prioritized based on existing needs and resources across all regions.

Two international transcultural instruments were developed to allow the systematic description of mental health services across countries. The European Service Mapping Schedule (ESMS) [11] was designed to compile an inventory of mental health service structures, describing their major characteristics and listing the provision of health, social, and voluntary and private sector services, whereas the International Classification of Mental Health Care (ICMHC) [12] was designed to describe and classify procedures and interventions delivered within mental health facilities [12]. Responding to the increasing problems related to mental disorders in Ghana, coupled with the challenges in service delivery, requires a systematic assessment and description of mental health services in Ghana using an international transcultural instrument that can serve as a platform to systematically describe these services. We considered both the ESMS and ICMHC in our study.

Neither the ESMS nor ICMHC had previously been used in any study in Ghana, although the ICMHC had been used in a comparative study conducted in Norway and Russian [13] to describe mental health services in the two countries. We found the ESMS suitable for developing a systematic description of mental health services in Ghana, whereas we used the ICMHC to describe the level of interventions aimed at improving mental health services. We expect the findings of this study to provide more comprehensive evidence for mental health planning, with the strategies identified targeting the management and improvement of mental health services at the community level on a nationwide basis.

\section{Study Objective}

The main objective of this study was to provide a systematic description of mental health services in Ghana. The description of the services focused on 1) mental health resources and the organization and use of mental health services, 2) the decentralization and differentiation of mental health services, and 3) possible interventions to improve mental health service delivery.

\section{Methods}

\subsection{Study Setting}

The study was conducted in Ghana. The Republic of Ghana lies within the latitude $4^{\circ} 44^{\prime} \mathrm{N}$ and $11^{\circ} 11^{\prime} \mathrm{N}$ and $3^{\circ} 11^{\prime} \mathrm{W}$ and $1^{\circ} 11^{\prime} \mathrm{E}$. Ghana a bordered by the Republic of Togo to the east, Burkina Faso to the north-west and north, and the 
Republic of Cote d'Ivoire to the west. The Gulf of Guinea, which is part of the Atlantic Oceans lies south of the country, and it forms a $550 \mathrm{~km}$-long coastline. The Volta River basin, including the artificially created Lake Volta, dominates the country's drainage system. The population distribution is varied across the 10 administrative regions (currently 16 regions) and eco-zones of the country, with $68 \%$ and $32 \%$ living in the rural and urban areas respectively. About $52 \%$ of the labour force is engaged in agriculture, $29 \%$ in service and $19 \%$ in industry. Approximately, 39\% of farm labour force is women. Agriculture contributes to $54 \%$ of Ghana's GDP, and accounts for over $40 \%$ of export earnings, while at the same time providing over $90 \%$ of the food needs of the country. Ghana's agriculture is predominantly smallholder, traditional and rain-fed [14].

Ghana is a democratic republic with a population of 25,904,598 million people with $59.1 \%$ between the ages of 15 and 64 years [15]. Ghana has been considered a middle-income country since 2015 [16]. As a middle-income country, economic disparities persist between southern urbanized and northern rural Ghana. These economic disparities have affected access to quality mental health services among most of the population. The population distribution of the selected regions for this study include Ashanti $(4,780,380)$, Brong Ahafo (2,310,983), Central $(2,201,863)$, Eastern $(2,633,154)$, Greater Accra $(4,010,054)$ and Northern $(2,479.461)$. Farming, handicraft and fishing are the most common occupation in the rural areas of the regions. However, official staff, trading and selling, transportation, industry and manual labour are the most common occupations in the urban areas of the regions [14].

We selected six hospitals from ten regions for this study. Only the Central and Greater Accra Regions have specialized psychiatric hospitals, and the mental health services in the selected regions face many challenges due to inadequate resources. The hospitals and the regions are Tafo Government Hospital in $\mathrm{Ku}$ masi, Ashanti; Sunyani Reginal Hospital in Brong Ahafo; Ankaful Psychiatric Hospital in the Central; Koforidua Regional Hospital in the Eastern region; Accra Psychiatric Hospital in Greater Accra; and Tamale Teaching Hospital in the Northern Regions. We selected hospitals in these regions to enable us to obtain representative data from a wider geographical area on mental health services from all parts of the country, from the south to the north of Ghana. These regions have a mixture of urban, semi-urban, and rural populations.

On February 12, 2019, six additional new regions were created in Ghana, which affected two of the study regions. Two new regions were created from the Brong Ahafo Region, and two regions were created from the Northern Region [17]. This did not introduce limitations to the data collection and analysis in this study.

\subsection{Study Design}

A cross-sectional study was conducted for data collection between September 2018 and August 2019. The study design enabled us to categorize our findings into themes for the description of mental health services and prevented manipu- 
lation of the research participants. Furthermore, this study design allowed us to describe various variables of interest at the same time, and it was suitable for descriptive analysis of the data on mental health services.

\subsection{Study Participants and Sampling Procedure}

We used the snowball technique to select 42 mental health professionals from six hospitals in six regions in Ghana for the study. The first author established initial contact with the hospital administrators, directors of medicine, and nursing managers (to fulfill administrative procedures) in the selected hospitals and presented them with an ethical clearance letter from the Ghana Health Service Ethics Review Committee. He then explained the goal of the study and described the required participants (mental health professionals) to the hospital authorities. The nursing managers were directed to lead the research team to select the study participants. The nursing managers introduced the research team to mental health charge nurses in each hospital to take part in the study. The mental health charge nurses also led the research team to select the required informants to form the research groups in each hospital. This process of selecting the research informants was repeated in each of the selected hospitals. The snowball technique improved our communication with the samples in each hospital. The risk of bias was low as the sampled populations were homogeneous in nature.

Each hospital provided seven mental health professionals to participate in the study. The total sample consisted of 17 (45.2\%) male and 23 (54.8\%) female professionals, all over the age of 19 . The first author met the required informants in each hospital and explained the goal of the study and procedures of the research questionnaire to the research participants and answered participants' questions. This was done to ensure that the participants clearly understood the study and could respond adequately for data collection and analysis. Moreover, explaining the research procedure promoted understanding, respect for, and the dignity of the research participants, enabled participants to provide informed consent, and fulfilled the required autonomy criteria. We allowed research participants 14 days to confirm their participation before providing each of them with the consent form approved by the Ghana Health Service Ethics Review Committee, which they signed. Research participants were also informed that participation was voluntary and that by signing the consent form, they all had the right to withdraw from the study at any time without any threat or disadvantage.

\subsection{Research Instrument}

Before developing the research instrument for data collection, the following observed factors were considered to enable us to realise our objective. We decided on the required information that could meet our objective for this study, we defined our study subjects, we decided on the technique of reaching out to the study subjects, we decided on the content of the questionnaire, we developed the wording for the questionnaire, we grouped the questionnaire into a meaningful 
order, we revised the length of the questionnaire, the questionnaire was pretested, and we developed the final questionnaire form that was used for data collection.

The research instrument was pilot tested from July to November 2016 in all the hospitals. This enabled us to make adjustments to the administrative aspect of the study. For instance, we made adjustments to the length of time the interviews will take in each hospital compared with the planned length of time as well as checking the appropriateness of the timing of the study in regard to time of meeting the study subjects for data collection. Of the two instruments initially considered, namely the ESMS and ICMHC, we found the ESMS more applicable to collecting and describing data on mental health services in Ghana. The ESMS has been used in other national studies [18] [19] and international studies [13] [18] [20] and proved to be applicable for the description of mental health services.

The first author initially trained seven mental health professionals from each hospital to elicit information using the ESMS. The interviews included sociogeographical variables; resources for mental health services; the organization, decentralization, differentiation, and interventions of mental health services; faith-based mental health services; mental health services in prisons and schools; and interventions aimed at improving mental health services. We used the ESMS to classify mental health services into three main categories: residential (inpatient), community (outpatient), and day and structured services. Moreover, the English version of the instrument was used.

The ICMHC was used only to describe data on mental health interventions in Ghana. The instrument is based on interventions that are readily available in mental health care that are categorized in a system of ten "modalities of care". A "modality of care" is "a category comprising all those interventions that can possibly be applied to achieve one of the restricted numbers of task that together comprise the whole range of mental health care" [12].

\subsection{Data Collection}

We collected data in the hospitals selected for the study. We selected the hospitals and regions included in the study to ensure a fair representation for the data collection. Furthermore, we sought administrative approvals and permissions from the Ghana Health Service Ethics Review Committee and the Mental Health Authority. We used a structured interview questionnaire to conduct face-to-face interviews with the study subjects $(n=42)$ at the various hospitals where they worked. We held interview sessions twice, and we interviewed each participant twice. The first set of interview sessions was held from May to July 2018, and the second set from September 2018 to August 2019. However, we replaced Komfo Anokye Teaching Hospital with Tafo Government Hospital, Kumasi, in the Ashanti Region on 1 May 2019 because we could not meet the demand for further ethical approval due to the time frame for data collection and bureaucratic requirements of the hospital. We conducted interviews twice at Tafo Govern- 
ment Hospital, Kumasi, between June and August 2019 with the assistance of one general practitioner and one mental health charge nurse.

We recorded the data from the final interview sessions in the field notes and used them in our analysis. We summarized the data from the field notes based on the interview questionnaire, before conducting a theme-based analysis. The first author also conducted telephonic conversations with participants during the analysis of the data to clarify responses. The data collection was done by the first author, who is a specialist public health physician; a general practitioner; and six mental health senior staff nurses. All interviews lasted for an estimated duration of 2 hours (120 minutes) in the afternoons on the hospital premises.

\subsection{Data Analysis}

We used a systematic approach to analyse and describe data based on themes. The analysis was based on mental health services in all hospitals selected for this study. We analysed and described data just as reported by respondents from the field notes. Our analysis focused on the sociodemographic information of the respondents, which included gender, age, profession, work experience, educational level, and the region of work. We classified age into three categories: 1) 19 to 24 years; 2) 25 to 34 years; and 3) $\geq 35$ years. Educational attainment was classified by level of education. For this analysis, each respondent was classified under university (general practitioners and physician assistants) and college level (mental health charge nurses and mental health nurses).

We further analysed and described data on the resources for, organization of, and use of mental health services, decentralization of services (primary care, day treatment, inpatient, and outpatient) and differentiation of services. Additionally, we analysed and described data on mental health services provided by faithbased healers, a term that refers in this study to those who offer mental health services using herbal medicine and operators of prayer camps offering unregulated mental health services. We also analysed and described mental health services in schools and prisons, which we found to be an important part of mental health service delivery. Furthermore, we analysed mental health service interventions and measured the interventions using ICMHC intervention codes to rate the effects of interventions aimed at delivering mental health services in Ghana.

In our analysis of the data, we used cross-tabulations, which prevented confusion and enhanced insight into important data that may have been overlooked in the description of variables of interest in our analysis.

\section{Results}

Forty-two mental health professionals completed this study; the dropout rate was zero. More female respondents $(23 ; 54.8 \%)$ participated than male respondents $(19 ; 45.2 \%)$. The age distribution comprised $4.8 \%$ at 19 to 24 years, $63.3 \%$ between the ages of 25 and 34 years, and $31.0 \%$ of the respondents were $\geq 35$ 
years. More mental health nurses $(54.8 \%)$ participated in the study groups than other mental health professionals who took part in the study, but no difference was observed in the male mental health charge nurses and the male mental health nurses because we recorded the same proportions (42.1\%). Most respondents $(64.3 \%)$ had attained a college education, and $45.2 \%$ had six to 10 years of working experience. The characteristics of the participants, separated by gender, are presented in Table 1.

Table 1. Characteristics of a cross-sectional survey of 42 mental health professionals.

\begin{tabular}{|c|c|c|c|}
\hline \multirow{2}{*}{ Characteristic } & \multirow[b]{2}{*}{ Total } & \multicolumn{2}{|c|}{ Gender } \\
\hline & & Male & Female \\
\hline$n(\%)$ & 42 & $19(45.2)$ & $23(54.8)$ \\
\hline \multicolumn{4}{|l|}{ Age in years } \\
\hline $19-24$ & $2(4.8)$ & - & $2(8.7)$ \\
\hline $25-34$ & $27(64.3)$ & $14(73.7)$ & $13(56.5)$ \\
\hline$\geq 35$ & $13(31.0)$ & $5(26.3)$ & $8(34.8)$ \\
\hline \multicolumn{4}{|l|}{ Professional qualification } \\
\hline General practitioners & $2(4.8)$ & $2(10.5)$ & $1(5.9)$ \\
\hline Mental health charge nurses & $13(31.0)$ & $8(42.1)$ & $5(29.4)$ \\
\hline Mental health nurses & $23(54.8)$ & $8(42.1)$ & $8(47.1)$ \\
\hline Physician assistants & $4(9.5)$ & $1(5.3)$ & $3(17.6)$ \\
\hline \multicolumn{4}{|l|}{ Educational level } \\
\hline University & $15(35.7)$ & $11(44.0)$ & $8(47.1)$ \\
\hline College & $27(63.3)$ & $12(48.0)$ & $9(52.9)$ \\
\hline \multicolumn{4}{|l|}{ Work experience (in years) } \\
\hline $1-5$ & $16(38.1)$ & $8(42.1)$ & $8(34.8)$ \\
\hline $6-10$ & $19(45.2)$ & $8(42.1)$ & $11(47.8)$ \\
\hline$\geq 11$ & $7(16.7)$ & $3(15.8)$ & $4(17.4)$ \\
\hline \multicolumn{4}{|l|}{ Regions } \\
\hline Ashanti Region & $7(16.7)$ & $4(21.1)$ & $3(13.0)$ \\
\hline Brong Ahafo Region & $7(16.7)$ & $3(15.8)$ & $4(17.4)$ \\
\hline Central Region & $7(16.7)$ & $3(15.8)$ & $4(17.4)$ \\
\hline Eastern Region & $7(16.7)$ & $3(15.8)$ & $4(17.4)$ \\
\hline Greater Accra Region & $7(16.7)$ & $3(15.8)$ & $5(21.7)$ \\
\hline Northern Region & $7(16.7)$ & $4(21.1)$ & $3(13.0)$ \\
\hline
\end{tabular}

\subsection{Human Resources Distribution in the Selected Hospitals}

Table 2 provides an overview of human resource staff in the selected hospitals. Ankaful Psychiatric Hospital, one of the biggest hospitals, employs few doctors and physician assistants. The result indicates that the nursing workforce is the backbone of mental health services. The zero values on the table reflect the weakness 
Table 2. Human resource distribution for core clinical staff in the hospitals.

\begin{tabular}{cccccccc}
\hline \multirow{2}{*}{ Staff } & \multicolumn{7}{c}{ Hospitals by region } \\
\cline { 2 - 8 } & ACPH & ANPH & KRH & SRH & TGH & TTH & Total \\
\hline Psychiatrist & 3 & 3 & 1 & 0 & 0 & 0 & 7 \\
Other MDs & 6 & 1 & 0 & 0 & 0 & 0 & 7 \\
All nurses & 586 & 275 & 16 & 10 & 14 & 17 & 918 \\
Pharmacist & 3 & 1 & 0 & 0 & 0 & 0 & 4 \\
Clinical psychologist & 1 & 0 & 2 & 1 & 1 & 1 & 6 \\
Occupational therapist & 0 & 0 & 0 & 0 & 0 & 0 & 0 \\
Social welfare officers & 4 & 2 & 3 & 2 & 0 & 0 & 11 \\
Clinical psychiatrists & 3 & 2 & 0 & 9 & 0 & 0 & 14 \\
Physician assistants & 20 & 4 & 0 & 0 & 1 & 0 & 25 \\
Total & $\mathbf{6 2 6}$ & $\mathbf{2 8 8}$ & $\mathbf{2 2}$ & $\mathbf{2 2}$ & $\mathbf{1 6}$ & $\mathbf{1 8}$ & $\mathbf{9 9 2}$ \\
\hline
\end{tabular}

ACPH-Accra Psychiatric Hospital, ANPH-Ankaful Psychiatric Hospital, KRH-Koforidua Regional Hospital, SRH—Sunyani Regional Hospital, TGH-Tafo Government Hospital, and TTH—Tamale Teaching Hospital.

in mental health human resources in Ghana. Furthermore, all the hospitals lack occupational therapists; only Accra Psychiatric Hospital, Ankaful Psychiatric Hospital, and Tafo Government Hospital have pharmacists; and general practitioners are present only in the two main psychiatric hospitals. Tafo Government Hospital has the lowest staffing level (16) in the group.

In Table 3, the distribution of regional mental health personnel is presented. The results show that most personnel are either community psychiatric nurses (745) or registered mental nurses (263). The Brong Ahafo, Central, and Northern regions have no psychiatrists at the regional level. The total number of the psychiatrist (9) in all regions is slightly higher than regional mental health coordinators (6). Very few enrolled nurses (5) are offering mental health services in general in three regions ( 1 in Ashanti, 2 in Eastern, and 2 in Northern). The table further illustrates that the Northern region has the lowest number of mental health personnel (72) compared with the rest of the regions in the study.

Table 4 presents national figures from 2017 of the use of mental health resources in all public facilities in Ghana. Few psychiatrists and psychologists are available per 100,000 people. Likewise, the number of community mental health officers (72/100,000 population) is also low. Additionally, only one day-treatment centre, one children's ward, and three psychiatric hospitals exist. Equally discouraging is the 1322 hospital beds for all psychiatric hospitals, with an estimate of 440/100,000 population per hospital, and 123 outpatient facilities delivering mental health services. Generally, mental health resources are limited.

\subsection{Residential (Inpatient) and Community (Outpatient) Facilities for Mental Health Services}

Our survey indicated the existence of only four residential units, which are 
Table 3. Distribution of mental health personnel by region in the study.

\begin{tabular}{ccccccccc}
\hline Region & Psychiatrist & RMHC & $\begin{array}{c}\text { Clinical } \\
\text { psychologist }\end{array}$ & $\begin{array}{c}\text { Clinical } \\
\text { psychiatric } \\
\text { officers }\end{array}$ & CPN/RMN & CMHO & EN & Total \\
\hline Ashanti & 4 & 1 & 4 & - & 198 & 32 & 1 & 240 \\
B/A & 0 & 1 & 1 & 9 & 130 & 45 & 0 & 186 \\
Central & 0 & 1 & 1 & 0 & 128 & 30 & 0 & 160 \\
Eastern & 1 & 1 & 2 & 0 & 193 & 44 & 2 & 243 \\
G/A & 4 & 1 & 5 & 8 & 85 & 54 & 0 & 157 \\
Northern & 0 & 1 & 0 & 0 & 11 & 58 & 2 & 72 \\
Total & 9 & $\mathbf{6}$ & 13 & $\mathbf{1 7}$ & $\mathbf{7 4 5}$ & $\mathbf{2 6 3}$ & $\mathbf{5}$ & 1058 \\
\hline
\end{tabular}

Note: Data obtained from Ghana Mental Authority Report (2017). B/A-Brongahafo, G/A-Greater Accra, RMHC - regional mental health coordinator, CPN-Community psychiatric nurse, RMN - Registered mental nurse, CMHO-Community mental health officer, and EN-Enrolled nurse.

Table 4. Resource use in all the population.

\begin{tabular}{cc}
\hline Staff Codes & Total per 1000 population \\
\hline Psychiatrists & 18 \\
Psychologist & 19 \\
Registered Mental Health Nurses (all hospital) & 1068 \\
Community mental health nurses & 72 \\
Social workers & 21 \\
Outpatient facilities & 123 \\
Psychiatric hospitals & 3 \\
Community based psychiatric inpatient units & 7 \\
Community residential facilities & 4 \\
Day treatment centre & 1322 \\
Children's ward & 1 \\
Children's bed & 15 \\
\hline
\end{tabular}

Data obtained from Ghana Mental Health Authority Report (2017).

located far away from densely populated regions. The units provide 112 beds, with patients spending an average of 365 days in the units. Moreover, our survey revealed 123 outpatient facilities for mental health services in Ghana. Most patients treated in outpatient units were 20 years and older, and 61,341 patients were treated in outpatient facilities in 2017 for organic mental disorders, substance abuse, schizophrenia, epilepsy or seizures, neurotic disorders, bipolar disorder, major depressive disorder, mental retardation, adult personality and behavioural disorders, and mood disorders in all hospitals.

\subsection{Day and Structured Treatment Services}

Our results indicate that day and structured services focus on patients who need 
daytime psychiatric services to cope with life. Only one day-treatment facility exists in Ghana, and it is operated by the Roman Catholic Church. The day treatment centre provides structured daily mental health services such as psycho-education, pastoral care, the improvement of psychomotor skills, occupational therapy, and leisure activities as a form of support to those living with mental illness. Furthermore, the facility had one therapist, one registered psychiatric nurse, and one hospital assistant as of 2017, based on our survey, and more women than men used the services provided.

\subsection{Primary Health Care Mental Health Services}

Primary health care mental health services are either physician based and nonphysician based. The respondents reported that services are based on treatment guidelines. Mental health nurses and non-physicians are not allowed to prescribe medications, and psychotropic and other medications are prescribed only by physicians at the primary health care centres. Furthermore, at least one psychotropic medication in each therapeutic category (antidepressant, antipsychotic, mood stabilizers, anxiolytics, and antiepileptic) is available and accessible at physician-based primary health care centres.

\subsection{Faith-Based Mental Health Facilities}

Some religious groups and traditional herbal practitioners in Ghana offer mental health services through prayer camps and shrines. Our survey showed that 1253 people were "treated" in 2011, of which 470 (37.5\%) were female and 783 (62.5\%) in other treatment groups (males and other genders). These practitioners followed no formal or standardized treatment protocol, and they did not consider ICD-10 in their practices. We found that faith-based practitioners treated conditions such as substance abuse, mood disorders, epilepsy, and depression without any reliable evidence of diagnosis.

\subsection{Differentiation of Mental Health Services}

We identified three levels of mental health services. During residential (inpatient) mental health services, patients are diagnosed, and treatment is prescribed. The patients are put under the close care of mental health professionals in the hospital until they are discharged. This is done to ensure that patients are kept out of the environments that might have been associated with the cause of their mental disorders. Day and structured services begin after patients are discharged from the hospital, and a review date is set for reporting to the hospital and for follow-ups. Structured activities that focus on improving patient social connectedness in the community are prescribed to help in recovery. Community (outpatient) services also continue when a patient is discharged and is entrusted into the hands of the community mental health nurses for monitoring, reporting, and recommendation for further treatment. Community services allow patients to continue to be in their homes with their families to continue with their respon- 
sibilities while undergoing treatment.

Table 5 indicates the reporting of mental health services in schools and prisons by gender. Overall, $66.7 \%$ of respondents reported that there are trained resident mental health professionals on prison premises. Opinions on whether specialized outpatient departments for prisoners exist were evenly divided (50.0\%), whereas $54.8 \%$ of respondents reported that there are no specialized wards for prisoners. However, $90.5 \%$ of the respondents reported that most prison officers have received mental health training. Additionally, $54.8 \%$ of respondents reported limited mental health educational materials and most schools lacking trained resident mental health professionals, while $81.0 \%$ reported that schoolteachers have not received mental health training. This perception was held by $89.5 \%$ of male and $73.9 \%$ of female respondents.

Table 5. Perception of mental health services in prisons and schools by gender.

\begin{tabular}{|c|c|c|c|}
\hline \multirow{2}{*}{ Characteristic } & \multirow[b]{2}{*}{ Total } & \multicolumn{2}{|c|}{ Gender } \\
\hline & & Male & Female \\
\hline$n(\%)$ & 42 & $19(45.2)$ & $23(54.8)$ \\
\hline \multicolumn{4}{|c|}{ Trained resident mental health professionals in prisons } \\
\hline Yes & $28(66.7)$ & $12(63.2)$ & $16(69.6)$ \\
\hline No & $14(33.3)$ & $7(36.8)$ & $7(30.4)$ \\
\hline \multicolumn{4}{|c|}{ Prison officers with mental health training } \\
\hline Yes & $38(90.5)$ & $18(94.7)$ & $20(87.0)$ \\
\hline No & $4(9.5)$ & $1(5.3)$ & $3(13.0)$ \\
\hline \multicolumn{4}{|c|}{ Special outpatient departments for prison } \\
\hline Yes & $21(50.0)$ & $9(47.4)$ & $12(52.2)$ \\
\hline No & $21(50.0)$ & $10(52.6)$ & $11(47.8)$ \\
\hline \multicolumn{4}{|c|}{ Specialized wards for prisons } \\
\hline Yes & $19(45.2)$ & - & $19(100)$ \\
\hline No & $23(54.8)$ & - & $23(100)$ \\
\hline \multicolumn{4}{|c|}{ Trained mental health professionals in schools } \\
\hline Yes & $19(45.2)$ & - & $19(100)$ \\
\hline No & $23(54.8)$ & - & $23(100)$ \\
\hline \multicolumn{4}{|c|}{ Enough mental health education materials } \\
\hline Yes & $19(45.2)$ & - & $19(100)$ \\
\hline No & $23(54.8)$ & - & $23(100)$ \\
\hline \multicolumn{4}{|c|}{ School teachers with mental health training } \\
\hline Yes & $8(19.0)$ & $2(10.5)$ & $6(26.1)$ \\
\hline No & $34(81.0)$ & $17(89.5)$ & $17(73.9)$ \\
\hline
\end{tabular}

In Table 6, the perceived challenges of mental health education are listed by gender. Overall, $57.1 \%$ of the respondents reported that the most common challenge of mental health education in schools in Ghana is inadequate funding. 
Table 6. Major challenges of mental health education.

\begin{tabular}{cccc}
\hline \multirow{2}{*}{ Characteristic } & \multicolumn{3}{c}{ Gender } \\
\cline { 2 - 4 } & Total & Male & Female \\
\hline$n(\%)$ & 42 & $19(45.2)$ & $23(54.8)$ \\
Inadequate funding & $24(57.1)$ & $14(73.7)$ & $10(43.5)$ \\
Transportation challenges & $9(21.4)$ & $3(15.8)$ & $6(26.1)$ \\
Inadequatemental health educational materials & $9(21.4)$ & $2(10.5)$ & $7(30.4)$ \\
\hline
\end{tabular}

Transportation challenges and inadequate mental health education materials were reported by $21.4 \%$. More male respondents $(73.7 \%)$ than female respondents $(43.5 \%)$ reported inadequate funding. More female than male respondents also reported transportation challenges $(26.1 \%$ vs. $15.8 \%)$ and inadequate mental health educational materials ( $30.4 \%$ vs. $10.5 \%$ ).

Table 7 shows the level of the proportions of interventions of mental health services.

Generally, EMRE, which encompasses activities that involve patients in the health care process, was moderately rated by $54.8 \%$ of respondents. Overall, PROB, which involves diagnostic and regular assessment activities applied to monitor the treatment process; ADLF, which involves activities to take care of patients who are incapable of taking care of themselves; and PSYC, which involves activities that include relapse prevention, sense of self, personal aspirations, relationships, education, social inclusion, and the ability to be self-dependent, were moderately rated at $69.0 \%$ respectively. Regarding PROB, more female than male respondents rated it as moderate ( $73.9 \%$ vs. $63.2 \%)$. Additionally, the women reported higher (78.3\%) for ADLF compared with the men (57.9\%), whereas the results of PSYC reported by the women (69.6\%) was slightly higher than the male respondents (68.4\%). GENC, which focuses on activities that involve general mental health care within a defined model of care, was also moderately rated by $59.5 \%$ of the respondents. Moreover, FARM was moderately rated by $57.1 \%$, with slightly more male respondents $(57.9 \%)$ ascribing this rating than female respondent (56.5\%).

The interventions rated low were COOR, which focuses on activities that guarantee that patients have access to relevant available resources and services in care and treatment processes; REHB, which involves educating and re-educating patients on interpersonal and social skills, and helping individuals to spend their days in the most worthwhile way to them; and FAML, which involves activities to involve families and society in the management of mental conditions. They achieved the same results (59.5\%). Most female respondents (69.6\%) ascribed a low rating to FAML, whereas male respondents ascribed a low and moderate rating to FAML with the same results (47.4\%). The overall observation showed that the interventions aimed at improving mental health services were moderately rated by most of the respondents in the study. 
Table 7. Mental health service interventions in Ghana based on ICMHC codes.

\begin{tabular}{cccc}
\hline \multicolumn{2}{c}{${ }^{1}$ ICMHC intervention codes } & \multicolumn{2}{c}{ Gender } \\
\hline$n(\%)$ & Total & Male & Female \\
\cline { 2 - 4 } & 42 & $19(45.5)$ & $23(54.8)$ \\
\hline EMRE: Establishing and maintaining relationships with patients \\
High & $17(40.5)$ & $9(47.49)$ & $8(34.8)$ \\
Moderate & $23(54.8)$ & $9(47.4)$ & $14(60.9)$ \\
Low & $2(4.8)$ & $1(5.3)$ & $1(4.3)$
\end{tabular}

PROB: Problem assessment

$\begin{array}{cccc}\text { High } & 13(31.0) & 7(36.8) & 6(26.1) \\ \text { Moderate } & 29(69.0) & 12(63.2) & 17(73.9) \\ \text { Low } & - & - & -\end{array}$

COOR: Care coordination

$\begin{array}{cccc}\text { High } & 2(4.8) & 1(5.3) & 1(4.3) \\ \text { Moderate } & 15(35.7) & 7(36.8) & 8(34.8) \\ \text { Low } & 25(59.5) & 11(57.9) & 14(60.9)\end{array}$

GENC: General health care

$\begin{array}{cccc}\text { High } & 16(38.1) & 9(47.4) & 7(30.4) \\ \text { Moderate } & 25(59.5) & 9(47.4) & 16(69.6) \\ \text { Low } & 1(2.4) & 1(5.3) & -\end{array}$

ADLF: Taking over activities of daily living

$\begin{array}{cccc}\text { High } & 13(31.0) & 8(42.1) & 5(21.7) \\ \text { Moderate } & 29(69.0) & 11(57.9) & 18(78.3) \\ \text { Low } & - & - & -\end{array}$

FARM: Psychopharmacological interventions

$\begin{array}{cccc}\text { High } & 17(40.5) & 8(42.1) & 9(39.1) \\ \text { Moderate } & 24(57.1) & 11(57.9) & 13(56.5) \\ \text { Low } & 1(2.4) & - & 1(4.3)\end{array}$

PSYC: Psychological interventions

$\begin{array}{cccc}\text { High } & 13(31.0) & 6(31.6) & 7(30.4) \\ \text { Moderate } & 29(69.0) & 13(68.4) & 16(69.6) \\ \text { Low } & - & - & -\end{array}$

REHB: Interventions helping patients to cope with impairment

$\begin{array}{cccc}\text { High } & 6(14.3) & 4(21.1) & 2(8.7) \\ \text { Moderate } & 11(26.2) & 7(36.8) & 3(13.0) \\ \text { Low } & 25(59.5) & 7(36.8) & 18(78.3)\end{array}$

FAML: Interventions aimed at family and society

\begin{tabular}{cccc} 
High & $2(4.8)$ & $1(5.3)$ & $1(4.3)$ \\
Moderate & $15(35.7)$ & $9(47.4)$ & $6(26.1)$ \\
Low & $25(59.5)$ & $9(47.4)$ & $16(69.6)$ \\
\hline
\end{tabular}

${ }^{1}$ International Classification for Mental Health Care (2000) Codes for Interpretation. 


\section{Discussion}

The description of mental health services in our study-the first in Ghana that has systematically described mental health services with the use of an international transcultural instrument-provides a comprehensive overview of how mental health services are delivered in Ghana. Mental health services in Ghana are both hospital and non-hospital based. General physicians are the first point of contact for mental patients, but their services are inadequate due to scant resources. Nevertheless, "patients on long-term admission for treatment stay in the hospital for 365 days" on average according to the Ghana Mental Health Act 846, 2012 (p. 21). Non-hospital-based services are linked with unregulated mental health services provided by faith-based healers and operators of prayer camps. However, non-hospital based mental health services are also linked with services provided by the community mental health mobile teams under the Mental Health Authority.

Our findings showed that the quality and availability of the general mental health services are delivered at a moderate rate in Ghana. The quality and availability of mental health services regarding taking over daily living activities of patients (ADLF), problem assessment of mental disorders (PROB), and psychological interventions (PSYC) are common in all the hospitals. Our results are consistent with the 2017 Ghana Mental Health Authority report, which stated that the quality and availability of the mental health services are moderately delivered due to the inadequate resources at all levels of service delivery. In this study, our sample group consisted of mental health professionals selected from six hospitals. These respondents-two general practitioners working in the mental health unit, 13 mental health charge nurses, 23 mental health nurses, and four physician assistants-played a pivotal role in enhancing the data collection. They participated in the activities in all phases of this study (preparation, training on the procedures of the study, and data collection).

\subsection{Strengths and Limitations of the Study}

The study has several strengths. We used the ESMS for the first time in Ghana to describe mental health services. Additionally, the snowball sampling technique yielded positive results by allowing us to draw on the expected sample while also preventing manipulation of the research environment. The common medium of instruction (English) used for interviews improved the effectiveness of the research and ensured full participation of research participants during the interview sessions. Finally, hosting two interview sessions enhanced the clarity of the data collected. However, our inability to include a detailed analysis of private orthodox mental health services in Ghana, is a significant limitation.

\subsection{The Organization of Mental Health Services in Ghana}

The organization of mental health services, which requires both material and human resources, faces enormous challenges. Until the establishment of the 
Mental Health Act 846 in 2012, major factors contributing to these challenges included the lack of an established body for the organization of mental health services and the chief psychiatrist's focus on planning and organizing services only at the national level. We observed that the lack of supervision of mental health services at the local level may have affected the organization of mental health services before 2012, but during this period, mental health professionals did deliver services in various public hospitals. The implementation of the Mental Health Act 846 in 2012 led to the decentralization of the chief psychiatrist's responsibilities, diffusing them from the national to the regional, district, and community levels. Thus, despite the persistent lack of resources for mental health services, the implementation of the Act brought some relief.

As Thornicroft and Rose (2005, pp. 13-614) noted, the provision of mental health services should be balanced, with services including both community and hospital services, depending on the resources available [21]. With the resource limitations in the mental health care system, "primary care with specialist backup" should be considered as the most appropriate means of delivering mental health services [22], with general practitioners playing primary roles. Kazakovtsev (2003, p. 66-68) further found that most patients with mental disorders who require inpatient services are likely to meet a general practitioner before being referred to a mental health professional for further treatment [23].

Yet we observed weak collaboration between general practitioners in the primary health care centres and mental health professionals in our study, despite the aim of the Ghana Mental Health Act 846 to help bridge this gap. A factor contributing to this weak collaboration may be explained by unexplained lapses for instance, lack of space in the organization of mental health services. The Mental Health Act of 2012 (p. 10) aims to develop a multidisciplinary human resource plan for the basic, advanced, and continuing development of staff. Little has been achieved in terms of staff development; therefore, we suggest that multidisciplinary human resource development should also focus on strengthening the collaboration between mental health professionals and the general practitioners in primary care centres to enhance the organization of mental health services.

Moreover, most outpatient clinics are understaffed. Overall, the available mental health services are moderately organized. While this holds true for urban areas, services in rural areas are poorly organized. This calls for further investigation because respondents were unable to clearly define the reason for this variation between organization of urban and rural mental health services.

\subsection{Resources for Mental Health Service Delivery}

Resources are vital for the effective delivery of mental health services. However, in Ghana, resources are inadequate for mental health service delivery. This may be explained by the decades-long neglect of the field of mental health. Our survey showed that despite the hope to improve mental health services attached to the implementation of the Mental Health Act 846, inadequate resources for the 
implementation of policies has been a great challenge. The field of mental health has failed to attract enough funding to acquire resources towards improving mental health services because of limited capacity building for mental health research [24] [25].

Furthermore, although the Mental Health Act 846 (p. 34) delineates the establishment of a mental health fund to provide resources for the care and management of persons suffering from mental disorders, limited funding is available to finance mental health service delivery due to an inadequate national health budget. These funding limitations could explain why the Mental Health Act 846 (p. 9) promotes the use of existing facilities at the primary, district, and regional levels to create psychiatric units for the delivery of mental health services instead of the construction of new infrastructure, which is probably a better option. Moreover, due to resource constraints, primary health care centres are prioritized over psychiatric hospitals to use the limited resources available for delivering mental health services. This may have caused low outpatient consultations in the primary health care centres compared with high outpatient consultations in psychiatric hospitals. Dmitrieva in 2004 suggested that there is a need for outpatient services for mental disorders, coupled with the need for adequate resources and infrastructure to improve mental health service delivery [26].

Further, our findings show that inpatient care comes with the challenge of inadequate psychiatric beds for patients. The respondents reported that relatives of patients see hospital admission as the best option to rid themselves of patients and as a dumping point for patients living with mental disorders. In addition, some relatives provide incorrect contact information to the hospital to avoid being located when patients are discharged from the hospital. Respondents further noted that when successfully contacted, many relatives "do not show up". In cases like these, patients remain a burden to the hospitals and are left in the hands of philanthropists. Nurses also experience hostility from patients' relatives when these relatives are invited to discuss further treatment recommendations. Our recommendation is improving collaboration between the hospitals, patients' relatives, and the minister of state in charge of social welfare, who, according to the Mental Health Act (p. 30), is responsible for making available psychosocial facilities such as supervision, rehabilitation, and vocational training for patients after they receive hospital care. This can be achieved by making available the facilities to engage the discharged patients to help them contribute to society.

We further assessed the resources of faith-based healers and operators of prayer camps, as society has accepted their methods of providing mental health services. Our findings indicate that patients with mental disorders who visit these healers have no access to proper housing, water, clothing, food, and security due to a lack of resources. Additionally, these healers have no scientific skills and knowledge of the management of mental disorders; they depend solely on supernatural powers. However, we could not establish any association between their method of rendering mental health service and any scientific method.

We recommend that since society has accepted these healers, periodic training 
programmes based on scientific principles with certification be organized, focusing on equipping faith-based healers and operators of prayer camps with basic knowledge and skills in handling mental patients. The training should also focus on mandating them to provide a standardized state-of-art facilities for patient and work within contextual systematic scientific protocols. We believe that the training will ensure proper monitoring, evaluation, and reporting of the activities of faith-based healers and prayer camps to augment the promotion of mental health services while preventing harm to innocent individuals.

\subsection{Decentralization and Deinstitutionalization of Mental Health Services}

Through the process of deinstitutionalization and decentralization, mental health services shift from the primary health care centres to the main psychiatric hospitals. However, there are limitations to following the international trend of deinstitutionalization and decentralization in mental health services [27]. We found that mental health services in Ghana remain largely in psychiatric hospitals, and decentralization and deinstitutionalization has been weak. In addition, limited beds are available in the psychiatric wards of most primary health centres in Ghana. According to our survey, the structured day treatment services, which requires the availability, accessibility, and use of both material and human resources, are hospital-based and focused on patients who require daytime psychiatric support. Moreover, there is only one day-treatment centre in Ghana. This is a disadvantage to most of the patients who need daytime mental health services. The centre is inaccessible for most of the population and overburdened in terms of the high patient number, inadequate resources, and limited space. We recommend the expansion and establishment of new day treatment centres to accommodate those who require day treatment services.

Furthermore, we found that the mental health services delivered at primary health centres are mostly physician based, with limited resources. The only strength of these centres is the availability of psychotropic medications (antidepressant, antipsychotic, anti-epilepsy, and anticonvulsant medications), which registered mental health physicians prescribe. This finding is consistent with the results of other studies. For instance, Saxena in 2011 (p. 56-7) indicated in his study that most mental health services in low- and middle-income countries are physician based, with poor infrastructure, which hampers the improvement of mental health service delivery [28]. Additionally, according to Goldberg and Huxley's (1980) model, general practitioners should be responsible for primary health care in mental health services. Moreover, poor professional interaction and collaboration between general practitioners and mental health professionals remains problematic. Studies addressing the collaboration between mental health care and primary care focused on: 1) the evaluation of existing collaboration models between mental health service and primary care [29] [30] [31]. 2) integration of mental health service into primary care [32] [33] [34] [35] [36] and 3) management of mental disorders in the primary care [37] [38] [39]. Ac- 
cording to the respondents, the challenges inherent in professional interactions and collaboration have affected referral systems, as some general practitioners sometimes fail or feel reluctant to make referrals to mental health professionals when necessary for further assessment, diagnosis, and treatment of patients living with mental disorders. The challenges of professional collaboration and interaction may be explained by weaknesses in the organization and decentralization of mental health services and limited infrastructure and diagnostic equipment.

According to research, the diagnosis and treatment of mental disorders in low-middle-income countries and most low-resource settings within high-income countries occur in centralized psychiatric hospitals. Diagnosis, treatment, and referrals in primary care and community centres are typically lacking due to ineffective collaboration, interaction, and referrals systems [40]. To improve professional collaboration and enhance the interaction between general practitioners and mental health professionals in Ghana, we recommend conducting research to promote the understanding of integrating mental health services into general health care services at all levels of health care [41]. Further, policymakers should consider the Mental Health Action Plan 2013-2020, adopted by the World Health Assembly in 2013 as a way to develop and implement interventions to reduce mental disorders in all countries [25]. We found that the goal of reducing mental disorders cannot be achieved with poor professional collaboration and interaction between general practitioners and mental health professionals and with poor infrastructure.

We further analysed and described residential mental health services. We found that a limited number of residential units are available, possibly due to the financial challenges related to operating residential units or constructing additional units. There are only four residential units in Ghana, which are affected by infrastructure and human resource limitations. Our results are consistent with the 2011 Ghana Health Service report, which stated that only four residential units with 112 beds are available. The report also noted that the limited funding to run the residential units makes it challenging to provide mental health services for those who require residential services. Additionally, these residential units are far from most individuals living with mental disorders who require residential services; these patients cannot access residential services. Studies have confirmed that most people who require mental health services in low-middle-income countries typically cannot access care because they live far from the centralized psychiatric hospitals [4]. Poor organization and the decentralization of mental health services further contribute to this problem.

Several studies have shown that expanding and integrating mental health services into primary care has faced challenges in various countries [42] [43] [44]. This also applies to Ghana, as our results are consistent with this finding. Common challenges of integrating mental health care into primary health care in Ghana include limited infrastructure, limited human resources, and less community awareness of mental health; poverty and social deprivation; a high rate of 
comorbidity with physical problems; high levels of stigma and discrimination; and variations in mental health conditions which influence the acceptability and uptake of services which have also been found and discussed in other studies [24] [40] [45]. While Ghana has made efforts to legislate mental health reforms and move towards deinstitutionalization, these efforts have not been adequately formulated to meet mental health care needs. Additionally, mental health research is lacking in Ghana, and societal misconceptions exist about mental health in general.

According to the WHO, "the promotion of mental health education for vulnerable individuals in economically and socially disadvantaged groups will improve mental health outcomes and reduce the crime rate" [46] when resources for education are made accessible, affordable, and available. The respondents who took part in this study stated that community mental health nurses periodically visit schools to offer mental health education, but nurses are faced with resource constraints. Most respondents (54.8\%) reported a lack of materials for mental health education and pointed out that transportation to the schools and communities is also a challenge. Interventions in schools to promote mental health services are common in high-income countries [47] and middle-income countries [48]. But in most low-middle-income countries, not only in Ghana, school interventions are lacking [49], making it a challenging to improve school mental health services.

Our survey indicates a decrease in outpatient treatment in $2017(61,341)$ compared with 2016 (64,703). Admissions increased from 2311 in 2016 to 2356 in 2017, with discharges decreasing to 2194 in 2017 compared to 2341 in 2016. These figures represent clients who received services through all public psychiatric hospitals in Ghana. Most clients treated were women. The respondents did not identify a reason for the high number of women treated. However, our observation showed that the high rate of women with mental illness may be associated with how societal institutions have been constructed to disadvantage women. We also observed power relations between men and women, and gender inequality, in Ghanaian society. Women also generally have fewer societal protections regarding household decision-making and reproductive rights. According to our survey, women are subjected to various kinds of intimate partner violence, which respondents did not clearly define.

\section{Respondents' Perceptions of Mental Health Services in Prisons and Schools}

We described respondents' perceptions of the mental health services in prisons and schools in Ghana. The WHO reported that more than one-third of the prison population have mental conditions [46]. Our result showed that the majority $(66.7 \%)$ of the respondents believed there are trained resident mental health professionals on prison premises. Half of respondents believed there are specialized outpatient departments for prisoners, whereas half disagreed. Additionally, 54.8\% reported that even though there are specialized outpatient departments, there are no specialized wards for prisoners, and $90.5 \%$ reported that 
most prison officers have received mental health training. The Mental Health Act 846 (p. 9) makes provision for mental health services for prisons, but in practice, services for prisons have not been fully implemented due to inadequate resources. We further found that weaknesses in mental health services for prisoners may be associated with the unestablished scope of services for prisoners in most health centres. A clear definition of the scope of services for prisoners is essential in improving mental health services for this sector of the population.

Moreover, we examined respondents' perceptions of whether schoolteachers have received mental health training. Respondents indicated that most teachers (81.0\%) have not received any mental health training, and $54.8 \%$ of respondents reported that schools also do not have trained resident mental health professionals on the school premises, especially boarding schools. We found that most mental disorders in students go undiagnosed because of the lack of trained resident mental health professionals on school premises and teachers' inability to detect and report mental disorders. We recommend that to help teachers and schools in reporting mental disorders for treatment, mental health education should be incorporated into the curriculum of schools in Ghana as well as training for schoolteachers on mental health.

\subsection{Differentiation of Mental Health Services}

Mental health service differentiation involves how services are organized and delivered at different levels; that is, residential (inpatient), community (outpatient), and day structured services. Studies have shown that the residential (inpatient) mental health services provided in primary health care alone is inadequate to meet the holistic needs for treatment access [41].

Residential mental health services in Ghana begin when a patient is diagnosed, and treatment is prescribed in the hospital. If the condition demands admission, the patient is admitted for further treatment. Patients are put under close observation by mental health professionals during treatment in the hospital until they are discharged. Patients are admitted to ensure that they are kept out of the environment that might have been associated with the cause of their mental disorder. Our survey also indicates that some psychiatric units in primary health facilities have no beds and space. Therefore, patients who require admission in these facilities are detained in the medical wards or referred to nearby hospitals that also have limited space and beds. This creates congestions in such hospitals.

Day and structured services begin after patients are discharged from the hospital, and a review date is set for reporting to the hospital. Further treatment recommendations are prescribed where necessary. During the day and structured services, patients are assigned structured activities that focus on improving their social connectedness to enhance their recovery processes.

Community (outpatient) services involve clinic-based follow-ups with mobile teams that conduct outreach clinics for individuals with mental condi- 
tions. It also includes interventions where patients receive psychological support through psychotropic medications such as antidepressants, anti-epileptic medications, mood stabilizers, antipsychotics, and anxiolytic medications. These medications are prescribed, are available, and are accessible, but their affordability remains unclear, although mental health services are supposed to be free, which requires further investigation. Our survey also showed that the community mental health nurses periodically report the progress of patients' recovery to the hospital and also report for further treatment when a relapse occurs or when necessary.

\subsection{Faith-Based Mental Health Services}

The belief in the Ghanaian community that mental disorders are influenced by supernatural forces and curses might have increased the prevalence of faith-based healers and prayer camps in mental health services. According to Mulatu (1999), people believe that supernatural forces may inflict mental illnesses on people if they cross these forces [50]. Participants in this study reported that most people seek mental health services from faith-based healers and operators of prayer camps because of their perception that mental disorders are caused by supernatural forces. Additionally, based on our findings, most Ghanaians may prefer alternative treatment sources to orthodox treatment because of financial constraints and negative societal perceptions about the cause of mental disorders and orthodox treatment procedures being unsatisfactory.

The WHO mandates member states to develop policies and laws that protect and promote human rights, with independent monitoring, to improve conditions in health facilities. This is in line with international human rights standards such as the United Nations Convention on the Rights of Persons with Disabilities [46]. In contrast to the concerns of international organizations, individuals living with mental disorders undergo torture at the hands of faithbased healers and operators of prayer camps. Individuals living with mental disorders are chained, starved, kept in tiny rooms, poorly fed, and poorly clothed. These healers offer inadequate accommodation and security services for their patients.

As stated in the Mental Health Act 846 (p. 23), "a person with a mental disorder is entitled to humane and dignified treatment at any time regarding personal dignity and privacy and has right to wear clothes while in a treatment facility and to maintain personal belongings subject to space limitation." We observed a clear violation of this act by these healers, which may be attributed to the lack of monitoring, evaluation, and reporting systems by the Mental Health Authority of Ghana, connected with weak enforcement of mental health regulations to control these healers. We observed a further violation of the Mental Health Act 846 (p. 72), which states that "any unaccredited facility under the health institutions and unaccredited facilities or a body recognized by the Ministry of Health shall not admit involuntary patients for treatment." Based on our findings, society has accepted these healers, but Mental Health Authority moni- 
toring, evaluation, and reporting systems have not been enforced.

Further, our study did not support the claim by faith-based healers and prayer camp operators that they successfully treat mental illnesses without following scientific protocols and without authentic statistics to substantiate their claim. Most patients who visit alternative healers are in appalling states when they return for orthodox treatment. We are not opposed to these healers. However, the Mental Health Authority should provide them with scientific training to enable them to apply scientific principles in their activities to reduce harm to individuals living with mental disorders.

\subsection{Interventions in the Mental Health Service System}

The focus of any mental health care system is to ensure the provision of quality services aimed at preventing disabilities and prolonging life. This view is based on available health interventions employed by various countries, including Ghana [1]. Mental health interventions in Ghana including general mental health education and education focusing on decreasing stigmatization, improving mental health infrastructure, as well as increasing mental health personnel aim to improve the quality of mental health services, despite all the attendant challenges. Further, mental health interventions have been discussed in other studies.

The WHO developed the "Mental Health Gap Action Programme International Guide through a systematic review of evidence, followed by an international participatory consultative process", to help countries to develop interventions towards improving mental health services [2]. The plan focuses on straightforward, user-friendly, diagnosis-specific, and "clinical guidelines for providing evidence-based practices. The guidelines can also be used by nonspecialized health care providers after adaptation for national and local needs". Nevertheless, the WHO guidelines contain interrelated challenges that contribute to exacerbating mental health intervention and treatment gaps across countries. The challenges include the shortage of mental health workers, lack of research capacity, stigmatization, and lack of infrastructural facilities [2]. Irrespective of the Mental Health Gap Action Programme International Guide, we used an international instrument to describe interventions in this study.

In our study, the ICMHC was applicable only to describing mental health service interventions in Ghana. Our findings show that mental health service provision in countries differs in terms of interventions because of the differences in resources. Countries with advanced resources, such as Norway, Sweden, and Denmark, are more likely to deliver better, more efficient mental health services compared with countries with fewer resources such as Ghana. Our findings also revealed that countries' socioeconomic levels may determine the effectiveness and efficiency of mental health interventions. Conversely, our analysis indicated that inadequate staffing and medications for primary health centres, negative perceptions about mental health among the population, and distance and cost of transportation to psychiatric hospitals may be additional factors affecting the ef- 
ficiency of mental health service interventions.

In our analysis, we rated the intervention modalities based on the codes of the ICMHC to as follows: 0 - 3 as low, $4-6$ as moderate, and 7 and above as high. In other studies, "trials conducted in low- and middle-income countries have demonstrated the efficacy and effectiveness of both psychopharmacological treatment and evidence-based psychotherapies for treating mental disorders" [42] [43] [47] [48] [51] [52] [53] [54] [55]. Our results indicate that the quality of psychopharmacological interventions was moderately delivered in Ghana. This may be explained by inadequate modern infrastructure and equipment for the determination of the serum level of medications in psychiatric hospitals. Most participants $(54.8 \%)$ rated interventions aiming at EMER ${ }^{1}$ moderately. $\mathrm{PROB}^{2}$, $\mathrm{ADLF}^{3}$, and $\mathrm{PSYC}^{4}$ were also moderately rated, each achieving the same result from $69.0 \%$ of respondents. We observed that relapse and social exclusion were the major challenges of psychological interventions due to negative societal perceptions about mental health and the ineffective supervision of caregivers. GENC ${ }^{5}$ was moderately rated by $59.5 \%$ of the respondents due to inadequate resources, while $\mathrm{FARM}^{6}$ was moderately rated by $57.1 \%$. The interventions that received a low rating- $\mathrm{COOR}^{7}, \mathrm{REHB}^{8}$, and $\mathrm{FAML}^{9}$ were reported by the same percentage of respondents (59.5\%). The low rating assigned to care coordination (COOR) may be associated with other factors such as poor professional collaboration with non-mental health professionals.

Irrespective of the severity of mental disorders, every health problem has a psychosocial dimension and recovery must be supported within the dimension concurrently with any appropriate and physiological treatments. Psychological and psychosocial interventions do not seem to be in essence anti-pharmacological interventions, however, there are equally effective as a pharmacologic treatment in mental disorders [56] and are counselled as coincident interventions with pharmacological treatment in mental disorders [56]. We recommend that intervention programmes should have access to adequate material and human resources to be efficient and reliable.

${ }^{1}$ Establishing and maintaining relationships with patients through activities that involve patients in the health care process.

${ }^{2}$ Problem assessment which involves diagnostic and regular assessment activities applied to monitor the process of treatment.

${ }^{3}$ Taking over activities of daily living, which involves activities to take care of patients who are not capable of taking care of themselves.

${ }^{4}$ Psychological interventions involving activities which include those focused on relapse prevention, sense of self, personal aspirations, relationships, education, social inclusion, and ability to be self-dependent.

${ }^{5}$ General health care focusing on activities which involve general mental health care within a defined model of care.

${ }^{6}$ Psychopharmacological intervention.

${ }^{7}$ Care coordination which focuses on activities that guarantee that patients have access to relevant available resources and services in care and treatment processes.

${ }^{8}$ Interventions that help patients to cope with impairments, which involves educating and re-educating them on Interpersonal and social skills as well as helping them to spend their days in the most worthwhile way to them.

${ }^{9}$ Interventions aiming at family and society which involves activities to get family and society involve in the management of mental disorders. 


\subsection{Conclusions}

The use of an international transcultural instrument to describe mental health services for the first time in Ghana has expanded the understanding of mental health services. Insight on mental health resources and their organization and use, differences in levels of mental health services, and interventions towards improving mental health services have been uncovered. Areas for improvement in the mental health service based on our observation include increasing resources for mental health service delivery, improving professional collaboration between mental health professionals and general practitioners, increasing public mental health education, providing periodic scientific training programmes with certification for faith-based healers and operators of prayer camps, and enforcing the regulations set by the Mental Health Authority.

Integrating mental health services into primary care, with an emphasis on strong and smooth organization and decentralization policies, is equally important. We further want to highlight that inpatient services alone, like specialized mental health services and community-based services alone, cannot provide holistic intervention, but well-resourced primary care should fill the gap. Recommendations for building mental health research capacity, focusing on dissemination and implementation of mental health policies to determine service delivery pathways and use of the resources available, should be embraced. We also suggest the establishment of at least one psychiatric hospital in each region in Ghana or the creation of psychiatric clinics with state-of-the-art facilities within the primary health centres in all regions.

This paper has provided an overview of mental health services in Ghana, drawing on specific themes, with examples and an emphasis on the views of mental health professionals. Important challenges and recommendations have been described to address a broad range of interests. Despite the significant challenges inherent in the current system, we do not condemn the present mental health services available in Ghana. Moreover, we welcome constructive recommendations derived for further studies in the same field.

\section{Acknowledgements}

I would like to acknowledge Dr. Isaac Duodu and Pastor Helen O. Badu (Fountain Care Hospital, Ghana), Dr. Adwoa Pinamang Appau (Accra Psychiatric Hospital), Dr. Kwaw Armah Arloo (Ankaful Psychiatric Hospital, Cape Coast), Winifred Sam (Koforidua Regional Hospital), Joseph Yere (Sunyani Regional Hospital), Faara A. Edward (Sunyani Prisons), Dr. Prince Boadu Owusu (Tafo Government Hospital, Kumasi), David Larbi (Tamale Teaching Hospital), Mavis Frimpong (A member of Rwanda Bar Association, CEO of Be Global Consult Limited, Accra, Ghana), Francis and Hannah Opoku (Ghana Revenue Authority, Kumasi), and all respondents for their support and for making data available. To Jenas Nyarko, my deepest gratitude for your most needed care, support and encouragement. That was a great comfort and relief. 


\section{Authors' Contributions}

M.A conceived the study and was in charge of the planning, direction, preparation of the samples, formulation of research questions and data collection. M.A. and E.A. jointly designed the methodology of the study. Formal data entry and technic for analysis was jointly performed by M.A. and M.I. The initial draft of the manuscript was written by M.A. Critical review, commentary and revision was prepared by M.A, M.I. and E.A. Final approval of the version to be published was approved by M.A, M.I. and E. A. The management of the activities leading to publication was completed by M.A. The project was supervised by E.A. and supported by Fountain Care Hospital, Ghana.

\section{Availability of Data and Materials}

The data that support the findings of this study are available on request from the corresponding author, M.A. The data are not publicly available due to privacy/ethical restrictions because the data contain information that could compromise the privacy of research participants

\section{Ethics Approval and Consent to Participate}

Ethical approval for the project was granted by the Ghana Health Service Ethics Review Committee (GHS-ERC) and the Ghana Mental Health Authority.

\section{Funding}

The project was funded by Fountain Care Hospital, Ghana (FCHS/ADM/015/0001). Fountain Care Hospital played no role in the design of the study, data collection, data analysis, interpretation of data and writing the manuscript.

\section{Conflicts of Interest}

The authors declared that they have no potential conflict of interest in this study.

\section{References}

[1] World Health Organization (2019) Universal Health Coverage (Summary Report). https://www.who.int/news-room/fact-sheets/detail/universal-health-coverage-(uhc)

[2] World Health Organization (2016) Mental Health GAP (mhGAP) Intervention Guide for Mental, Neurological and Substance Disorders in Nonspecialized Health Settings. Version 2.0, World Health Organization, Geneva.

[3] Field, M.J. (1960) Search for Security: An Ethno Psychiatric Study of Rural Ghana. Faber and Faberz, London.

[4] Whiteford, H.A., Degenhardt, L., Rehm, J., Baxter, A.J., Ferrari, A.J., Erskine, H.E., et al. (2013) Global Burden of Disease Attributable to Mental and Substance Use Disorders: Findings from the Global Burden of Disease Study 2010. The Lancet, 382 1575-1586. https://doi.org/10.1016/S0140-6736(13)61611-6

[5] Murray, C.J., Vos, T., Lozano, R., Naghavi, M., Flaxman, A.D., Michaud, C., et al. (2012) Disability-Adjusted Life Years (DALYs) for 291 Diseases and Injuries in 21 Regions, 1990-2010: A Systematic Analysis for the Global Burden of Disease Study 
2010. The Lancet, 380, 2197-2223. https://doi.org/10.1016/S0140-6736(12)61690-0

[6] Kohn, R., Saxena, S., Levav, I. and Saraceno, B. (2004) The Treatment Gap in Mental Health Care. Bulletin of the World Health Organization, 82, 858-866.

[7] Bass, J.K., Annan, J., McIvor Murray, S., Kaysen, D., Griffiths, S., Cetinoglu, T., et al. (2013) Controlled Trial of Psychotherapy for Congolese Survivors of Sexual Violence. The New England Journal of Medicine, 368, 2182-2191. https://doi.org/10.1056/NEJMoa1211853

[8] Rahman, A., Malik, A., Sikander, S., Roberts, C. and Creed, F. (2008) Cognitive Behaviour Therapy-Based Intervention by Community Health Workers for Mothers with Depression and Their Infants in Rural Pakistan: A Cluster-Randomised Controlled Trial. The Lancet, 372, 902-909.

https://doi.org/10.1016/S0140-6736(08)61400-2

[9] World Health Organization (2005) Mental Health Declaration for Europe (Summary Report). WHO, Copenhagen.

[10] World Health Organization (2005) Mental Health Action Plan for Europe (Summary Report). WHO, Copenhagen.

[11] Johnson, S., Kuhmann, R. and the EPCAT Group (2000) The European Service Mapping Schedule (ESMS): Development of an Instrument for Description and Classification of the Mental Health Services. Acta Psychiatrica Scandinavica, 102, 14-23. https://doi.org/10.1111/j.0902-4441.2000.t01-1-acp28-03.x

[12] De Jong, A. (2000) ICMHC: International Classification of Mental Health Care. Paper Edited by WHO Collaborating Centre for Research and Training in Mental Health. Department of Social Psychiatry, University of Groningen, Groningen. https://doi.org/10.1111/j.0902-4441.2000.acp28--04.x

[13] Rezvyy, G., Øiesvold, T., Parniakov, A., Ponomarev, O., Lazurko, O. and Olstad, R. (2007) The Barent Project in Psychiatry: A Systematic Comparative Mental Health Service Study between Northern Norway and Archangelsk County. Social Psychiatry and Psychiatric Epidemiology, 42, 131-139.

https://doi.org/10.1007/s00127-006-0141-4

[14] Food and Agricultural Organization of the United Nations (2019). http://www.fao.org/ghana/fao-in-ghana/ghana-at-a-glance/en

[15] Ghana Statistical Services Report (2010) Population and Housing Census. Summary Report.

[16] World Bank Group (2015) Ghana Overview. https://www.worldbank.org/en/country/ghana/overview

[17] Embassy of the Republic of Ghana-Denmark (2019) Ghana's New Regions and Their Capitals. Summary Report.

[18] Salvador-Carulla, L., Tibaldi, G., Johnson, S., Scala, E, Romero, C. and Munizza, C. (2005) Patterns of Mental Health Services Utilization in Italy and Spain: An Investigation Using the European Service Mapping Schedule. Social Psychiatry and Psychiatric Epidemiology, 40, 149-159. https://doi.org/10.1007/s00127-005-0860-y

[19] Brieger, P., Wetzig, F. and Bocker, F.M. (2003) Institutions and Services of Psychiatric Care in Saxony-Anhalt: Assessment with the European Service Mapping Schedule. European Psychiatry, 18, 145-147. https://doi.org/10.1016/S0924-9338(03)00034-8

[20] Becker, T., Hulsmann, S., Knudsen, H.C., Martiny, K., Amanddeo, F., Herran, A., Knapp, M., Schene, A.H., Tansella, M., Thornicroft, G., Vazquez-Barquero and the EPSILON Study Group (2002) Provision of Services for People with Schizophrenia 
in Five European Regions. Social Psychiatry and Psychiatric Epidemiology, 37, 465474. https://doi.org/10.1007/s00127-002-0591-2

[21] Thornicroft, G. and Rose, D. (2005) Mental Health in Europe. BMJ, 330, 613-614. https://doi.org/10.1136/bmj.330.7492.613

[22] Thornicroft, G. and Tansella, M. (2004) Components of Modern Mental Health Services: A Pragmatic Balance of Community and Hospital Care. British Journal of Psychiatry, 1856, 283-290. https://doi.org/10.1192/bjp.185.4.283

[23] Kazakovtsev, B.A. (2003) Modern Form of Psychiatric Care. Zhurnal Nevrologii $i$ Psikhiatrii Imeni S.S. Korsakova, 9, 66-68.

[24] Collins, P.Y. and Pringle, B.A. (2016) Building a Global Mental Health Research Workforce: Perspectives from the National Institute of Mental Health. Academic Psychiatry, 40, 723-726. https://doi.org/10.1007/s40596-015-0453-3

[25] Saxena, S., Saraceno, B. and Granstein, J. (2013) Scaling Up Mental Health Care in Resource-Poor Settings. In: Improving Mental Health Care: The Global Challenge, Wiley-Blackwell, Hoboken, 12-24. https://doi.org/10.1002/9781118337981.ch2

[26] Dmitrieva, T.B. (2004) Social Psychiatry as a Priority Trend in Psychiatric Science and Practice. Vestnik Rossiiskoi Akademii Meditsinskikh Nauk, 7, 11-15.

[27] Hansen, V. and Oiesvold, T. (2004) Community Psychiatry in the Sub-Arctic. Experiences with the Shift from Hospital-Based to Community-Based Psychiatric Services in Northern Norway. Epidemiologia e Psichiatria Sociale, 13, 73-77. https://doi.org/10.1017/S1121189X00003286

[28] Saxena, S. (2011) Human Recourses. Workforce. In: Mental Health Atlas, WHO, Geneva, 56-57.

[29] Goldber, D. and Huxley, P. (1980) Mental Illness in the Community; the Pathway to Psychiatric Care. Tavistock Publications, London.

[30] Gask, L., Sibbald, B. and Creed, F. (1997) Evaluating Models of Working at the Interface between Mental Health Services and Primary Care. British Journal of Psychiatry, 170, 6-11. https://doi.org/10.1192/bjp.170.1.6

[31] Younes, N., Hardy-Bayle, M.C., Falissard, B., Kovess, V., Chaille, M.P. and Gasquet, I. (2005) Differing Mental Health Practice among General Practitioners, Private Psychiatrists and Public Psychiatrist. BMC Public Health, 5, Article No. 104. https://doi.org/10.1186/1471-2458-5-104

[32] Harmon, K., Carr, V.J. and Lewin, T.J. (2000) Comparison of Integrated and Consultation-Laison Models for Providing Mental Health Care in General Practice in New South Walse, Australia. Journal of Advanced Nursing, 32, 1495-1466. https://doi.org/10.1046/j.1365-2648.2000.01616.x

[33] Lucena, R.J., Lesage, A., Elie, R., Lamontagne, Y. and Corbiere, M. (2005) Strategies of Collaboration between General Practitioners and Psychiatrist: A Survey of Practitioners' Opinion and Characteristics. The Canadian Journal of Psychiatry, 47, 750758. https://doi.org/10.1177/070674370204700806

[34] Strain, J.J., Mustafa, S., Flores, L.R., Smith, G., Mayou, R., Carvalho, S., Malt, U., et al. (2003) Consultation-Liason Psychiatry Literature Database (2003 Update) Part 1: Consultation-Liason Psychiatry Literature Database: 2003 Update and National Lists. General Hospital Psychiatry, 25, 378-385. https://doi.org/10.1016/j.genhosppsych.2003.08.001

[35] Ilchef, F. (2006) Diamonds in the Coalface: New Research in Consultation-Liason Psychiatry. Current Opinion in Psychiatry, 19, 175-179. https://doi.org/10.1097/01.yco.0000214344.37002.3e 
[36] Deraas, T., Hansen, V., Giæver, A. and Olstad, R. (2006) Acute Psychiatric Admission from an Out-of-Hours Casualty Clinic; How Do Referring Doctors and Admitting Specialists Agree? BMC Health Services Research, 6, Article No. 41. https://doi.org/10.1186/1472-6963-6-41

[37] Gavin, B., Cullen, W., O’Donoghue, B., Ascencio-Lane, J.C., Bury, G. and O'Callaghan, E. (2005) Schizophrenia in General Practice: A National Survey of General Practitioners in Ireland. Irish Journal of Medical Science, 174, 38-42. https://doi.org/10.1007/BF03169146

[38] Verdoux, H., Cougnard, A., Grolleau, S., Besso, R. and Delcroix, F. (2005) How Do General Practitioners Manage Subjects with Early Schizophrenia and Collaborate with Mental Health Professionals? A Postal Survey in South-Western France. Social Psychiatry and Psychiatric Epidemiology, 40, 892-898. https://doi.org/10.1007/s00127-005-0975-1

[39] Charles, J., Miller, G. and Ng, A. (2006) Management of Psychosis in Australia General Practice. Australian Family Physician, 35, 88-89.

[40] Eaton, J., McCay, L., Semrau, M., Chatterjee, S., Baingana, F., Araya, R., et al. (2011) Scale Up of Services for Mental Health in Low-Income and Middle-Income Countries. The Lancet, 378, 1592-1603. https://doi.org/10.1016/S0140-6736(11)60891-X

[41] Sweetland, A.C., Oquendo, M.A., Carlson, C., Magidson, J.F. and Wainberg, M.L. (2016) Mental Health Research in the Global Era: Training the Next Generation. Academic Psychiatry, 40, 715-720. https://doi.org/10.1007/s40596-015-0437-3

[42] Drake, R.E. and Latimer, E. (2012) Lessons Learned in Developing Community Mental Health Care in North America. World Psychiatry, 11, 47-51. https://doi.org/10.1016/j.wpsyc.2012.01.007

[43] Hanlon, C., Wondimagegn, D. and Alem, A. (2010) Lesson Learned in Developing Community Mental Health Care in Africa. World Psychiatry, 9, 185-189. https://doi.org/10.1002/j.2051-5545.2010.tb00308.x

[44] Razzouk, D., Gregório, G., Antunes, R. and Mari, J.D. (2012) Lessons Learned in Developing Community Mental Health Care in Latin American and Caribbean Countries. World Psychiatry, 11, 191-195. https://doi.org/10.1002/j.2051-5545.2012.tb00130.x

[45] Hanlon, C., Luite, N.P., Kathree, T., Murhar, V., Shrivasta, S., Medhin, G., et al. (2014) Challenges and Opportunities for Implementing Integrated Mental Health Care: A District Level Situation Analysis from Five Low- and Middle-Income Countries. PLoS One, 9, e88437. https://doi.org/10.1371/journal.pone.0088437

[46] World Health Organization (2011) Sixty-Fourth World Health Assembly. WHO (Summay Report), Geneva.

[47] Fazel, M., Hoagwood, K., Stephan, S. and Ford, T. (2014) Mental Health Interventions in Schools in High-Income Countries. The Lancet Psychiatry, 1, 377-387. https://doi.org/10.1016/S2215-0366(14)70312-8

[48] Vieira, M.A., Gadelha, A.A., Moriyama, T.S., Bressan, R.A. and Bordin, I.A. (2014) Evaluating the Effectiveness of a Training Program That Builds Teachers' Capability to Identify and Appropriately Refer Middle and High School Students with Mental Health Problems in Brazil: An Exploratory Study. BMC Public Health, 14, Article No. 210. https://doi.org/10.1186/1471-2458-14-210

[49] Betancourt, T.S. and Chambers, D.A. (2016) Optimizing an Era of Global Mental Health Implementation Science. JAMA Psychiatry, 73, 99-100.

https://doi.org/10.1001/jamapsychiatry.2015.2705

[50] Mulatu, M.S. (1999) Perceptions of Mental and Physical Illnesses in North-Western 
Ethiopia: Causes, Treatments, and Attitudes. Journal of Health Psychology, 4, 531549. http://hpq.sagepub.com/content/4/4/531 https://doi.org/10.1177/135910539900400407

[51] Lund, C., Tomlinson, M., De Silva, M., Fekadu, A., Shidhaye, R., Jordans, M., et al. (2012) PRIME: A Programme to Reduce the Treatment Gap for Mental Disorders in Five Low- and Middle-Income Countries. PLOS Medicine, 9, e1001359. https://doi.org/10.1371/journal.pmed.1001359

[52] Mehta, N., Clement, S., Marcus, E., Stona, A.-C., Bezborodovs, N., Evans-Lacko, S., et al. (2015) Evidence for Effective Interventions to Reduce Mental Health-Related Stigma and Discrimination in the Medium and Long Term: Systematic Review. British Journal of Psychiatry, 207, 377-384. https://doi.org/10.1192/bjp.bp.114.151944

[53] Patel, V., Weiss, H.A., Chowdhary, N., Naik, S., Pednekar, S., Chatterjee, S., et al. (2010) Effectiveness of an Intervention Led by Lay Health Counsellors for Depressive and Anxiety Disorders in Primary Care in Goa, India (MANAS, a Cluster Randomized Controlled Trial). The Lancet, 376, 2086-2095. https://doi.org/10.1016/S0140-6736(10)61508-5

[54] Semrau, M., Barley, E.A., Law, A. and Thornicroft, G. (2011) Lessons Learned in Developing Community Mental Health Care in Europe. World Psychiatry, 10, 217 225. https://doi.org/10.1002/j.2051-5545.2011.tb00060.x

[55] Thurman, D.J., Logroscino, G., Beghi, E., Hauser, W.A., Hesdorffer, D.C., Newton, C.R., et al. (2017) The Burden of Premature Mortality of Epilepsy in High-Income Countries: A Systematic Review from the Mortality Task Force of the International League against Epilepsy. Epilepsia, 58, 17-26. https://doi.org/10.1111/epi.13604

[56] National Collaborating Centre for Mental Health [NCCMH] (2014) Psychosis and Schizophrenia in Adults: The NICE Guideline on Treatment and Management (NICE Clinical Guideline 178). NICE National Institute for Health and Care Excellence (NICE) Clinical Guidelines (2009), London, 368-376. 